\title{
Analisa Matematik Karakteristik Detector Semikonduktor Silicon Tipe P sebagai Bahan Detector Partikel Radiasi Bermuatan
}

\author{
Gunarwan Prayitno*, Emilia Roza \\ Program Studi Teknik Elektro, Fakultas Teknik, \\ Universitas Muhammadiyah Prof. DR. HAMKA, Jakarta. \\ Jl. Tanah Merdeka no.6 Pasar Rebo Jakarta Timur \\ Telp. +62-21-87782739, Fax. +62-21-87782739, Mobile. +62-815-3543-3089
}

\begin{abstract}
Abstrak - Analisa Matemetik Karakteristik Detector Semikonduktor Silicon Tipe P Sebagai Bahan Detector Partikel Radiasi Bermuatan. Saat ini banyak alat pendeteksi radiasi partikel bermuatan dibuat oleh industry, khususnya industry yang bekerja dalam pengembangan peralatan dan komponen deteksi. Prinsip kerja detector semikonduktor dan detector gas isian adalah sama. Pada detektor tipe gas isian, ionisassi terbentuk pada tabung gas, sedangkan detektor semikonduktor ionisasi terbentuk pada lapisan intrinsic (terbentuk antara $p$ dan $n$ ). Untuk membentuk lapisan intrinsic pada semikonduktor tipe P (mayoritas hole), bahan semikonduktor tipe p harus dikompensasi dengan material lithium (mayoritas electron), sehingga akan terbentuk lapisan $p$ dan $n$, dengan metoda evaporasi dan doping (ion drift), proses pemasukkan atom lithium ke dalam struktur ikatan kristal silicon. Proses pembuatan detektor semikonduktor telah dilakukan dan berhasil, tetapi analisa secara matematik belum dilakuakn. Hasil akhir dari analisa matematis bertujuan meningkatkan kualitas detektor semikonduktor.. Analisa matematik akan menjawab, bahwa, baik tidaknya detektor semikonduktor dalam bekerja (mencacah radiasi parikel bermuatan), bergantung dari kualitas doping dan kedalaman/lebar lapisan intrinsic. Pengembangan dan penelitian lebih lanjut akan di buat detector solid state dengan bahan semikonduktor tipe berbeda.
\end{abstract}

\section{Pendahuluan}

Material semikonduktor merupakan material yang dapat berada dalam dua kondisi, kondisi pertama dapat bersifat isolator dan kondisi kedua dapat bersifat konduktor. Untuk mengubah material semikonduktor silicon tipe $\mathrm{P}$, menjadi material konduktor diperlukan suatu proses. Metode prose yang akan digunakan untuk mengubah karakter material silicon tipe $\mathrm{P}$ menjadi material detector yaitu metode evaporasi. Karakter bahan semi-konduktor silicon tipe P. mayoritas sifat pembawa muatan adalah hole (positron). Jadi untuk mengubah bahan silicon tersebut, yang mayoritas pembawa sifat adalah proton (hole), harus dikompensasi dengan atom yang kelebihan elektron, supaya terjadi keseim- bangan antar proton electron, bahan material yang dibutuhkan untuk mengkompensasi hole adalah lithium. Untuk mengkompensasi hole dibutuhkan metode drift.

\section{Dasar Teori}

Karakter Material Semikonduktor Silokon Tipe P Akan dijelaskan secara teori sifat karakter bahan semikonduktor silicon dengan pita energy. Yang dimaksud dengan pita energy ialah suatu level energy yang terdapat pada ikatan
Kristal bahan semikonduktor. Letak antar level energy pita konduksi dan pita level energy valensi berbeda. Diantar kedua level enegi pita tersebut terletak suatu level energy, diasebut level energy Fermi, lebih jelasnya lihat gambar 1.
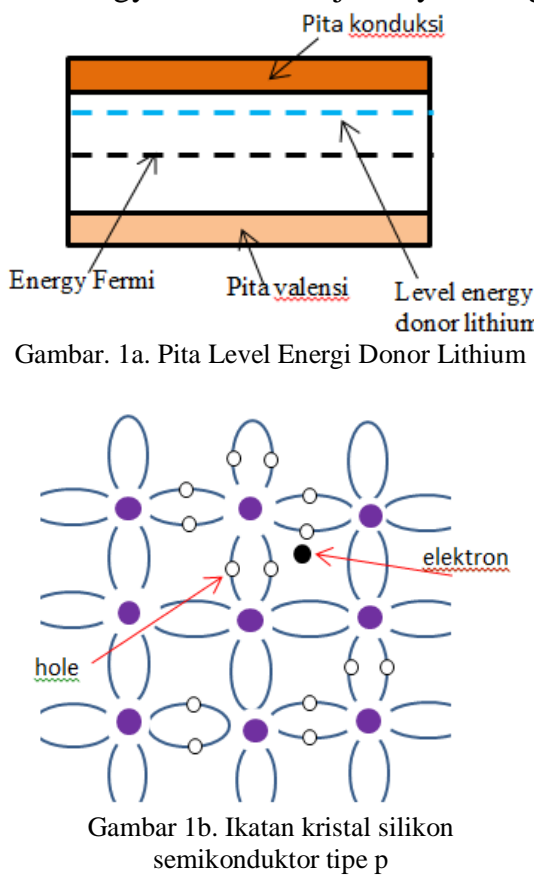
Dalam kristal silikon semua hole terikat oleh kristal tetangganya, namun ada sebuah elektron yang bebas tidak terikat. Dengan mayoritas hole maka letak pita energi dibawah level energi fermi, berada pada pita valensi. Sebelum di doping silikon bersifat bahan isolator, dengan mensubtitusikan elektron kedalam ikatan kristal silikon, itu berarti menaikan level pita energi, mendekati level pita energi konduksi (level energi donor). Telah dijelaskan bahwa dengan mendoping silikon dengan elektron untuk meng- kompensasi jumlah hole dengan elektron donor lithium. Sehingga akan mengakibatkan konsentrasi donor (elektron) akan sama dengan konsentrasi aceptor (hole), menurut persamaan 1 .

$$
\begin{aligned}
& n=N_{d}-N_{a} \\
& p=N_{a}-N_{d}
\end{aligned}
$$

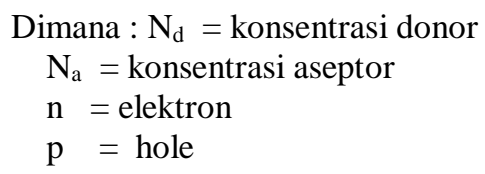

Bila terjadi keseimbangan antara donor dan aseptor maka perkalian antara minoritas carrier dan mayoritas carrier akan sama dengan muatan intrinsik $\left(\mathrm{n}_{\mathrm{i}}\right)$ carrier, menurut persamaan 2 .

$$
n \cdot p=n_{i}^{2}
$$

Doping atau pengotoran lthium bersrti menggantikan atom semikonduktor dalam kisi kristalnya. Dalam semikonduktor murni jumlah hole sama jumlah dengan elektron di dalam pita konduksi, kesetimbangan ini dapat berubah dengan memberikan pengotoran, dengan sejumlah atom pengotor atau doping yang mempunyai satu atau lebih elektron pada kulit atom terluarnya.

Jika pengotoran (doping) mempunyai ikatan trivalensi elektron, tidak akan cukup elektron untuk mengisi pita valensi, sehingga akan kelebihan hole. Oleh karena itu diperlukan atom pengontor yang mempunyai jumlah elektron pada kulit terluar lebih besar. Yang dapat melebihi jumlah hole dalam ikatan kistal.

$$
n \cdot p=n_{i}^{2}=N_{C} \cdot N_{V} \cdot \exp \left(\frac{E_{g}}{k T}\right) \ldots 3
$$

Dimana :

$\mathrm{N}_{\mathrm{C}}$ dan $\mathrm{N}_{\mathrm{V}}=$ kerapatan keadaan, pada bagian

tepi pita konduksi atau pita valensi,

$\mathrm{k}=$ konstanta Boltzman $=(\mathrm{kT}=0,0295 \mathrm{ev}$ pada temperature $\mathrm{T}=300^{\mathrm{O}} \mathrm{K}$ ).

conto perhitungan. Jila $\mathrm{n}_{\mathrm{i}}$ adalah konsentrasi pembawa intrinsic.

Pada $\mathrm{T}=300^{\circ} \mathrm{K}$, kita dapat $\mathrm{N}_{\mathrm{C}}=2,8 \times 1019$ dan $\mathrm{N}_{\mathrm{V}}=1,04$ x $10^{19}$, nilai khusus silikon.

\section{Proses Difusi Elektron Donor}

Proses difusi adalah perjalanan masuknya elektron donor (elektron lithium) kedalam ikatan kristal silikon (aseptor). difusi akan berlangsung atau terjadi dalam kondisi tertentu, artinya semikonduktor silikon tipe $\mathrm{p}$ dan lithium dikondisikan pada beberapa parameter, diberi temperatur tertentu dan tegangan tertentu, keduanya secara periodi dan bertahap ditingkatkan, dan dalam ruang tertentu. tujuan proses difusi ialah menciptakan lapisan intrinsik dalam semikondukto silikon tipe p. Bila proses berjalan dengan sempurna atau elektron donor dapat terdistribusi secara merata masuk kedalam ikatan kristal silikon, maka pembentukan lapisan intrinsik akan sempurna, artinya, nilai resistivity lapisan daerah intrinsik tinggi. akan tinggi. Parameter - parameter yang mempengaruhi tingginya resistivity pada lapisan daerah intrinsik, menurut persamaan 3 .

$$
j=\left(e \cdot n \cdot \mu_{D}^{n}+e \cdot p \cdot \mu_{D}^{p}\right)=E / \rho
$$

Dimana :

$$
\begin{aligned}
& \mathrm{e}=\text { muatan elektron } \\
& \mathrm{n}=\text { kerapatan elektron } \\
& \mathrm{p}=\text { kerapatan hole } \\
& \mathrm{E}=\text { medan listrik } \\
& \rho=\text { resistivity }
\end{aligned}
$$

Dengan persamaan diatas maka nilai resis- tivity dapat ditentukan dengan memanipulasi pesamaan tersebut menjadi, menurut per- samaan 4 .

$$
\rho=\frac{1}{e\left(\mu_{n} \cdot n+\mu_{p} \cdot p\right)} \ldots \ldots \ldots .
$$

Diman $\mu_{\mathrm{n}}$ adalah mobilitas elektron dan $\mu_{\mathrm{p}}$ mobilitas hole. Proses difusi dapat digambarkan seperti gambar 2 .

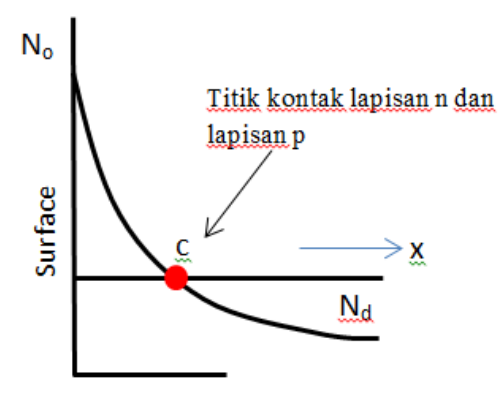

Gambar 2a. sebelum proses difusi elektron donor lithium

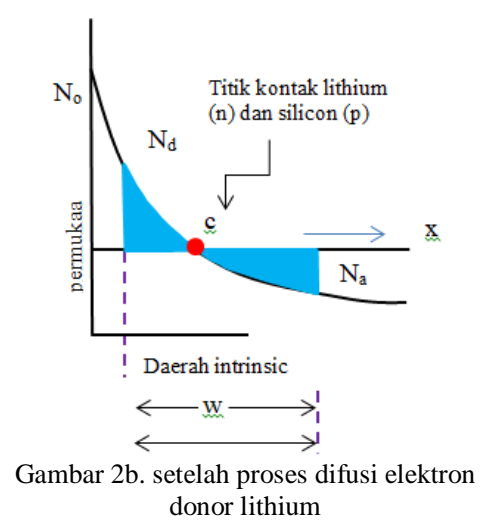


gambar 2a menunjukan sebelum proses difusi dan $2 \mathrm{~b}$ menunjukan setelah proses difusi, dan daerah yang diarsir biru merupakan daerah lapisan intrinsik terbentuk. Arti dari daerah yang diarsir mempunyai arti jumlah elektron donor sama dengan hole sama, No menjunjukan jumlah elektron kondisi awal, $\mathrm{N}_{\mathrm{d}}$ jumlah elektron donor, dan $\mathrm{Na}$ jumlah elektron aseptor (hole)

\section{Kompensasi Drift Lithium}

Proses drift akan dapat berlangsung bila wafer silikon dikondisikan dengan memberikan, tegangan, temperatur ,dan arus. Ketiga parameter secara periodik dinaikkan dengan sekala tertentu dandikontrol oleh alat grafik ploter. Proses kompensasi lithium terdiri dari 2 step, pertama pembentukan sambungan p-n, kedua menambah kedalaman ion lithium saat drift.

Pembentukan sambungan p-n dengan mendi- fusikan atom lithium kedalam silikon tipe p. kita katakan ion lithium sebagai donor $\left(\mathrm{N}_{\mathrm{d}}\right)$ dan semikonduktor silikon tipe $\mathrm{p}$ sebagai aseptor $\left(\mathrm{N}_{\mathrm{A}}\right)$. jika atom lithium mempunyai konsentrasi donor sebanyak N0, maka konsentrasi atim lithium yang didonorkan pada kristal semikonduktor tipe $\mathrm{p}$ adalah ;

$$
\begin{aligned}
& N_{d}=N_{0} \cdot \operatorname{erfc} c^{\left[\frac{1}{2} x\left(D_{0} t_{0}\right)-1 / 2\right.} \ldots \ldots \ldots . .5 \\
& N_{A}=N_{0} \cdot \operatorname{erfc} c^{\left[\frac{1}{2} x\left(D_{0} t_{0}\right)-1 / 2\right.} \ldots \ldots \ldots .6
\end{aligned}
$$

Perhatikan gambar 2a, konsentrasi lithium (Li) pada $\mathrm{x}<\mathrm{c}$ berkurang dan konsentrasi lithium pada $\mathrm{x}>\mathrm{c}$ bertambah. Konsentrasi lithium tidak akan dibawah nila NA pada $\mathrm{x}<\mathrm{c}$, nilai ND terus cenderung menuju NA pada $\mathrm{x}<\mathrm{c}$ dan menambah NA pada $\mathrm{x}>\mathrm{c}$, sehingga menghasilkan daerah intrinsik (w), lihat gambar 2b. Melalui daerah intrinsik dimana $\mathrm{N}_{\mathrm{D}}=\mathrm{N}_{\mathrm{A}}$, medan listrik $\mathrm{V} / \mathrm{w}$, dimana $\mathrm{V}$ adalah tegangan yang digunakan, menurut per- samaan 7 .

$$
J_{l}=\text { arus lithium ion } /_{\mathrm{cm}^{2}}=(V / w) \mu_{L} N_{A} \ldots \ldots \ldots \ldots 7
$$

Dimana $\mu_{L}$ mobilitas ion lithium didalam semikonduktor saat temperatur drift. Pertambahan ketebalan daerah intrinsik (w) dalam waktu dt, menurut persamaan 8 ,

$$
N_{A} d w=\left(\frac{V}{w}\right) \mu_{L} N_{A} d t
$$

Dengan mengintegrasikan;

$$
w=(2 \mu V)^{\frac{1}{2}} t^{\frac{1}{2}} \ldots \ldots \ldots 8
$$

Dimana V adalah tegangan pada daerah intrinsik.

\section{Sambungan Tipe P Dan N Semikonduktor}

Formasi pembentukan sambungan p-n membentuk lapisan khusus, disebut daerah intrinsik, yaitu daerah yang sensitif terhadap radiasi partikel bermuatan. Pada saat partikel radiasi

bermuatan melintas daerah intrinsic akan terbentuk pasangan ion positif dan ion negatif, gambar 3a. dan $3 \mathrm{~b}$. gambar 3a menunjukan kondisi forward bias atau daerah interisik diberi tegangan maju sesuai dengan majoriti ion yang ada pada masing-masing tipe $p$ (tegangan positif) tipe $\mathrm{n}$ (teganagan negatif). Untuk kondisi seperti tegangan maju daerah intrisik tidak mengalami pelebaran, artinya ion positif dan ion negatif tetap pada keadaan semula. Sedangkan pada gambar $3 \mathrm{~b}$. menunjukan tegangan reverse atau tegangan balik artinya sisi tipe $p$ diberi tegangan negatif dan sisi tipe $\mathrm{n}$ diberi tegangan positif. Pada kondisi ini daerah intrisik melebar, karena muatan ion pada masingmasing tipe akan tertarik ke arah kutup yang berlawanan.

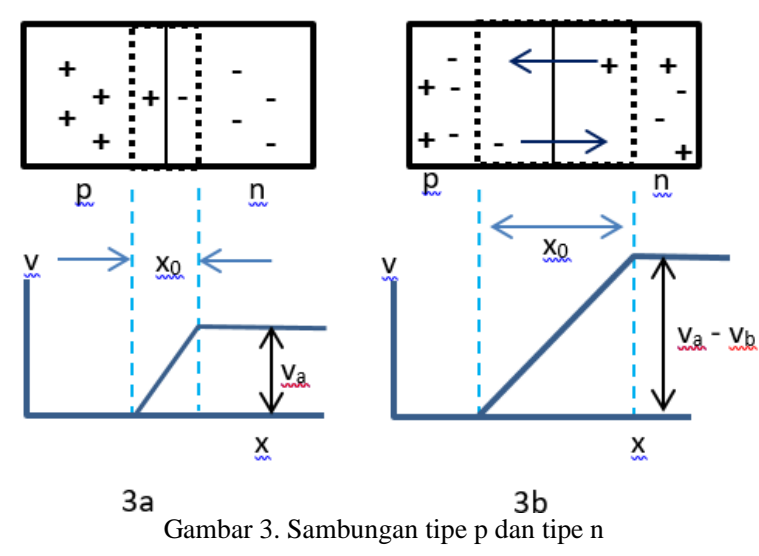

Jika tipe $\mathrm{p}$ dan tipe $\mathrm{n}$ bersambung bersama, elektron dan hole akan bergerak dengan alas -an;

1. Keduanya elektron dan hole akan bergerak dari konsentrasi tinggi ke konsentrasi ren- dah, ini merupakan konsep difusi.

2. Dibawah pengaruh medan listrik, kedua elektron dan hole akan bergerak ke arah yang berlawanan, sehingga berubah secara berurutan.

Karena berbedaan konsentrasi antara hole dan elektron diantara dua tipe semikonduktor, terjadilah difusi, hole akan berdifusi menuju daerah tipe $\mathrm{n}$, dan dengan cara yang sama elektron akan ke daerah tipe $\mathrm{p}$ (hole). Konsekuensinya elektron akan mengisi hile yang ada di tipe $\mathrm{p}$ (hole). Pada akhir proses difusi akan terjadi pada palisan daerah instrinsic tipe $\mathrm{n}$ menjadai mayoritas bermuatan positif, begitu juga sebaliknya daerah tipe $\mathrm{p}$ akan meyoritas elektron. Sehingga sebagai hasilnya akan terjadi keseimbangan jumlahm hole dan elektron sesuai dengan persamaan, (3). Hal ini dikenal sebagai potensial kontak. (Gambar 3a dan 3b), dimana nilai $\mathrm{v}_{\mathrm{a}}$ dan $\mathrm{v}_{\mathrm{a}}+\mathrm{v}_{\mathrm{b}}$ akan berbeda, hal ini bergantung dari konsentrasi hole dan elektron. Pada daerah kontak potensial ini di kenal sebagai daerah pemisah atau daerah intrinsik. Daerah ini sangat atraktif atau sensitif terhadap radiasi pertikel bermuatan, hole-elektron, kemudian akan berpisah dengan adanya medan listrik. Bila sambungan $\mathrm{p}$ dan $\mathrm{n}$ atau kontak potensial diberi tegangan dari luar. Tegangan $\mathrm{V}_{\mathrm{b}}$ bias positif dihubungkan ke sisi tipe n, maka potensial kontak akan menjadi $V_{a}+V_{b}$, hal ini sisebut (reverse bias). Keadaan ini akan menarik kedua hole-elektron pada kutub-kutub yang 
berbeda, mengakibatkan melebarnya daerah intrinsif, atau kontak potensial, sesuai dengan persamaan (9).

$$
x_{0}=\left[\mu_{\rho} \rho\left(v_{0}+v_{b}\right)\right]^{1 / 2}
$$

Dimana $V_{b}$ adalah riverse bias dan $V_{a}$ adalah kontak potensial, $\rho(\Omega-\mathrm{cm})$ resistivity semikonduktor dan $\mu_{\rho}$ adalah mobilitas hole. Jika potensial negatif dipasang pada sisi tipe $n$ maka terjadi efek positif pada sisi $n$. sehingga perbedaan potensial antara kontak potensial menjadi $\mathrm{V}_{\mathrm{a}}+$ $\mathrm{V}_{\mathrm{b}}$, hali ini disebut forward bias. Suatu detektor yang baik adalah bila dipasang tegangan reverse bias, akan terjadi $\mathrm{V}_{\mathrm{b}} \gg \mathrm{V}_{\mathrm{a}}$, maka lebar daerah pemisah atau lebar daerah intrinsik menjadi persamaa (10).

$$
X_{0}=\left(V_{b}\right)^{1 / 2}
$$

Sambungan P-I-N Semikonduktor Sebagai Detektor Solid State

Prinsip dasar operasi detektor semi- konduktor hampir sama dengan opersai detek- tor gas isian, (detektor tabung). Sebagai pengganti gas tabung dengan bahan semi konduktor, lebih jelas perhatikan gambar (4),

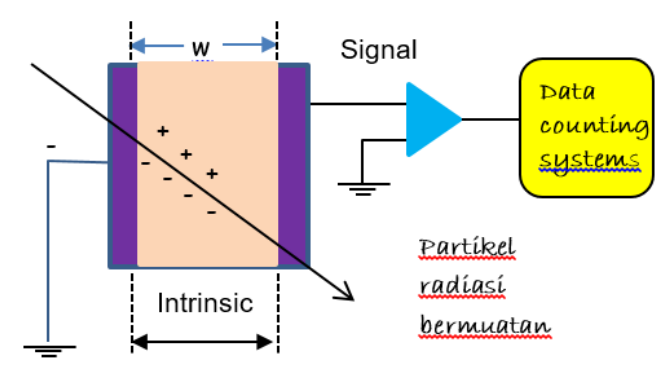

Gambar.4 prinsip kerja detektor semi konduktor.

Partikel radiasi yang masuk ke daerah intrinsuc akan menibulkan pasangan hole-elektron. Dengan adanya perbedaan tegangan yang diberikan secara eksternal, maka kedua pasangan hole-elektron akan tertarik pada tegangan yang bersesuaian. Sehingga akan timbul tegangan, tegangan ini diperkuat oleh rangkaian amplifier, kemudian di counting.

Akan diberikan contoh perhitungan jumlah pasangan ion hole-elektron yang terbentuk, bila partikel radiasi bermuatan masuk ke daerah intrinsic, misalkan radiasi pertikel berenergi $5 \mathrm{Mev}$, maka akan terbentuk pasangan ino hole-elektron sebanyak ;

$$
=\frac{5 \times 10^{6} \mathrm{eV}}{3 \mathrm{eV}}
$$

Waktu transit partikel radiasi bermuatan di daerah intrinsik dihitung dengan persamaan (11),

$$
t=\frac{d^{2}}{V_{a} \cdot \mu_{n}}=\cdots \operatorname{detik} \ldots \ldots
$$

Dimana d adalah kedalaman difusi daerah intrinsic, $\mu_{\mathrm{n}}$ adalah mobilitas elektron dan $\mathrm{Va}$ adalah tegangan yang digunakan. Jika masing-masing parameter tersebut diatas disubtitusi -kan maka ;

$$
t=\frac{(1,8)^{2}}{(500) \cdot(100)}=6,4 \times 10^{-7} \text { detik } \ldots \ldots
$$

Dengan contoh perhitungan jumlah pasangan ion holeelektron, maka arus rata-rata yang dihasilkan oleh satu partikel bermuatan adalah menghitung terlebih dahulu medan listrik di daerah intrinsic yaitu V/W (potensial listrik yang dipasang antara dua elektrode sisi $\mathrm{p}$ dan sisi $\mathrm{n}$, dibagi dengan lebar daerah intrinsik (w), dikalikan dengan mobilitas elektron selanjutnya dikalikan dengan bilangan avogadro $(\mathrm{Na})$. dalam persamaan matematis dituliskan dalam bentuk persamaan (12),

$$
\begin{aligned}
J_{l i}=\text { arus } L i \frac{\text { ion }}{c m^{2}}=\left(\frac{\text { hole-eletron pair }}{\text { waktu transit }}\right) \cdot \mathrm{Na} & \ldots \ldots \\
= & \frac{\left(1,7 \times 10^{6}\right) \cdot\left(1,6 \times 10^{-19}\right)}{6,4 \times 10^{-7}}=4 \times 10^{-7} \mathrm{amp} .
\end{aligned}
$$

\section{Simpulan dan Saran}

Sebagai detektor semikonduktor tipe silikon yang baik adalah bila perbandingan arus yang dihasilkan lebih besar dari arus noise. Mem -punyai nila resistivity yang tinggi, artinya dengan nilai tersebut maka daya henti terhadap partikel radiasi berenergi tinggi sangat baik, sehingga akan mengasilkan arus akan lebih besar. Untuk mendapatkan nilai resistivity yang besar dipengaruhi oleh kedalaman lapisan

intrinsic (saat proses difusi). Selain itu untuk harga resistivity $(\rho)$ yang tinggi dipengaruhi juga nilai mobilitas hole elektron yang tinggi, sehingga diharapkan waktu pengumpulan ion pasangan hole-elektron tersebut ke elektroda akan cepat. Sebelum pasangan terbentuk tertangkap atau sebelum ber-kombinasi kembali. Kondisi seperti ini memang sangat kontradiksi.

Luasan cakupan lapisan intrinsic dan arus noise permukaan detektor sangat berpengaruh terhadap performen detektor. Jadi dengan luasan permukaan lapisan sensitif detektor akan menambah pula arus bocor permukaan, yang pada akhirnya resolusi energi akan berkurang (kurang baik). Arus bocor permukaan pada detektor semikonduktor pada umumnya disebabkan saat fabrikasi atau pembuatan bahan material semikonduktor itu sendiri, baik tipe silikon atau germanium.

Biasanya dipengaruhi oleh kondisi lingkungan , kelembapan, dan waktu penyimpanan.

\section{Kepustakaan}

[1] S.M. Sze, Physics Of Semiconductor Device, 2 ${ }^{\text {nd }}$ ed, wiley, New York, 1981

[2] S.M. Sze, Semiconductor Device Physics And Technology, wiley, New York, 1985. 
[3] 3. Tsoulfanidis, Measurment and Detection Of Radiation, McGrawHill, New York, 1983.

[4] 4. Dearnaley and Northrop, Semiconductor Counter for Nuclear Radiation, 2nd ed, wiley, New York 1966.

[5] 5. William J Price, Nuclear Radiation Detection, 2nd ed, New York, 1964.
[6] Glenn F. Knoll, Radiation Detection and Measurment, 2nded, wiley, New York, 1989.

[7] A.S. Grove, Physics and Technology of Semiconductors Device, wiley,

New

York,

1967. 